\title{
The Effect of Using the E-Learning Management System (Jusur) on Knowledge Acquisition in the English Language and Achievement Motivation for Preparatory Year Students at the Hashimite University: An Empirical Study
}

\author{
Dr. Yaser Mohammad AL-adwan \\ The World Islamic Sciences and Education University, Jordan
}

\begin{abstract}
The research aims to prepare English language course through e-learning management system (JUSUR) for female students of preparatory year at the Hashemite University in Jordan; Identify the impact of using e-learning management system (JUSUR) on knowledge acquisition in the English language for female students of preparatory year at the Hashemite University in Jordan \& Identify the impact of using e-learning management system (JUSUR) on the motivation of the female students of the preparatory year at the Hashemite University. To achieve that goal the researcher conducting the post-test application on the students of the experimental group and control group in the period from 16/12/2016 until 20/12/2016 to identify the extent of the growth and improvement of the students to acquire certain cognitive skills attainment and achievement motivation in the subject of English for the students of the preparatory year.And thestudy results showed that there are differences with statistically significant at the level of $(0.05 \geq a)$ between the average scores of the experimental group and the control group average score in the post-test application for the experimental group.
\end{abstract}

Keywords: JUSUR- E-learning-LMS

\section{INTRODUCTION}

The concept of e-learning appeared with the advent of the technological revolution in information technology, which has made the world a small village, also contributed to the increasing need to share experiences with others, and the need for the student to rich multiple resources environments for making research and self-development, which is the mode of education in the delivery of science to the learner, depends on the modern technologies of the computer and the global network of information and its multimedia such as compact discs, interactive video, educational software, e-mail , virtual discussion and classroom dialogue and video conferencing and audio conferences, however, that e-learning are not seek for solutions instead of traditional education, but it seeks to support the learning process and facilitate the use of modern methods characterize the spatial and temporal flexibility.

Meaning it seeks to find a learning environment which integrates a set of tools with effective and efficient manner, as it contributes to increase interaction and communication between students with each other on the one hand and with lecturer on the other hand.

The e-learning supports the point of view based on student education as the focus of the educational process, where there are several tools available to them such as e-mail - electronic sources discussion Forum - chat rooms -Multimedia, While the traditional education is based on the lecturer and trainer (Atmezi,2007)

The distinction of e-learning with many unique features, also helped to resolve many of the difficulties faced by students and teachers, so countries have accelerated to provide education and training programs for its members through e-learning, therefore it is like, according to some studies and specialized research showing that $48 \%$ of colleges and conventional universities introduced its curricula directly online in 1998 , while the ratio to have risen $70 \%$ in 2000 . in contrast, there are universities not offer services and platforms only via internet such as University of Englewood and COLO and Kabila (Mousses ,1423) 
The great interest in the field of communications and computer techniques led to many important developments in the field of the use of computers in teaching and learning, and this interest represents the number of ways, including computer-assisted learning, online learning, distance learning and learning using virtual reality, i.e all forms of e-learning and related modern educational technology.

The e-learning is a form of development that we are seeing in the field of computer use in education, where became one of the important alternatives in spreading education and increasing the training, whether direct or indirect, e-learning is known as a way of learning by using modern communication mechanisms, such as computers, networks, multimedia voice, image and search mechanisms to electronic libraries and internet networks, whether remote or in the classroom, in order to achieve their educational goals, Accordingly e-learning is more comprehensive than just textbooks offered through websites and perspective should focus on the teaching and learning process management operations of the entire so-called learning management systems (LMS) (Mossi and Almubarak, 2005)

Where management system were not learning to manage all education and learning processes of recording, scheduling, availability of content, track student performance and issuing reports about that and communication between the teacher and the learners and among the learners themselves through chats, discussion forums, e-mail and file sharing, as well as the assessment tests and questionnaires

E-learning management system also allows the delivery of scientific material and keep track of learning and testing, communication and registration processes and study schedules and this is an integrated system for the management of the educational process in whole or in part via the Internet also includes the management of scheduled and drags synchronous and asynchronous Contact and manage tests and assignments and registration in courses and follow-up student. (CavusUzunboylu, Ibrahim, 2006)

That helps e-learning in the delivery of information to learners as soon as possible and less expensive due to overcome the constraints of space and time in the educational process and to provide an opportunity for learners to electronically interact immediately with each other on the one hand and between them and the teacher on the other hand through various means provided by.

And (warrier, 2006) refers to the e-learning features as marked by the strengthening of the students a sense of parity in the distribution of opportunities in the educational process and break the barrier of fear and anxiety they have and allow them to express their thoughts as well as taking into account individual differences among learners and give them an opportunity to search for facts and information means more than practiced in the traditional classroom, through easy access to the teacher even outside official working times, as well as providing a huge revolving balance of scientific content for each course can be developed and improved and more effective ways of teaching.

Academic achievement is one of the most important cognitive activities in which the standard of excellence or success or failure seems obvious to this, it is considered more linked activities to motivationto accomplish, and it is possible variation achievement motivation among learners and academic achievement variation (Anzi, 2003)

As a result of the effectiveness of E-learning and is characterized by its features have contributed to the development of the education process, it has become a modern educational methods that took a great deal of interest among educators in various countries around the world, many countries have sought to use e-learning, and for several reasons, including the increased need for education and increase the number of students (Zamil, 1425)

\section{RESEARCh Problem}

Increased importance of studying English as a second language at this age, and due to its spread across the world and being the language of many of the science and the production of knowledge, and with respect to their importance at the university level, it is one of the courses on which a lot of science and knowledge in various disciplines that are taught, so organizers of the higher education in the Kingdom of Jordan has decided to teach English as compulsory within the courses of the Preparatory year that the student must successfully pass to complete the march to the undergraduate college, here are highlights Jordanian universities efforts in the interest of this courses through cooperation with companies specialized in teaching English to recruit qualified staff to teach this 
The Effect of Using the E-Learning Management System (Jusur) on Knowledge Acquisition in the English Language and Achievement Motivation for Preparatory Year Students at the Hashimite University: An Empirical Study

courses, and the application of the latest methods that are compatible with the culture of Jordanian society, but the problem of the decline in the grades of students in this course preoccupied researcher for the duration of his work in teaching English language course for the students of the Faculty of Science and Arts for the Preparatory year at Jordan, and through observable the characteristics of the students of this stage as well as lower attainment,

In order to search for a solution to this problem, the need have emerged for the researcher to take advantage of e-learning environment provided by the Hashemite University, which is in the e-learning management system (JUSUR) through the content of electronic courses the English language and the study of its impact on the achievement of cognitive development and achievement motivation for students in the first semester.

Numerous studies such as the study (Zaylaa,2009) and study (Bukhari,2008) the importance of teaching the English language by using the diverse and modern methods of teaching, including elearning management systems to reach the desired goals of the teaching of this article, therefore, study the problem identified in the impact of the use of Learning Management System mail (JUSUR) on the acquisition of knowledge development and achievement motivation for thestudents of preparatory year at the Hashemite University, so the problem of the research is determined by answering the following main question:

What is the impact ofusing e-learning management system (JUSUR) on knowledge acquisition and achievement motivation for femalestudents of preparatory year at the Hashemite University?

The main question to emerge from the following sub-questions:

1. What is the impact of program used in the English language course through e-learning management system (JUSUR) on knowledge acquisition in the English language for students of preparatory year at the Hashemite University in Jordan?

3. What is the impact of program used in the English language course through e-learning management system (JUSUR) on achievement motivation in English language forfemale students of preparatory year at the Hashemite University in Jordan?

\section{RESEARCH GOALS}

The research aims to achieve several points, including:

1. Preparing English language course through e-learning management system (JUSUR) for female students of preparatory year at the Hashemite University in Jordan

2. Identify the impact of using e-learning management system (JUSUR) on knowledge acquisition in the English language for female students of preparatory year at the Hashemite University in Jordan

3. Identify the impact of using e-learning management system (JUSUR) on the motivation of the female students of the preparatory year at the Hashemite University

\section{RESEARCH IMPORTANCE}

The importance of this research stems through the following:

1. attempt to keep pace with contemporary global trends and in response to many of the recommendations of the research and conferences advocated employing technological innovations in the educational process to achieve the quality of education and the learning process, for example, Mohammad study (2010)

2. The study focused on a period of the most important stages of education, a university level and that is the responsibility of its members responsible for the preparation of individuals who will lead the development in the field of educational process

3. This research focuses on knowledgeacquisition and achievement motivation in English using a new technology tool students for female students of preparatory year at the Hashemite University in Jordan, after their use of the system (JUSUR) for e-learning tools, and who became one of the patterns of modern learning that keep pace with scientific and technological progress through the integration of technology and communication technologies in various university courses 
4. The advantage of this study is to try to develop e-learning at some colleges in the Hashemite University experience and mainstream application of this experience in the rest of the university faculties

\section{RESEARCH HYPOTHESIS}

This research sought to check the following assumptions:

1. There are differences with statistically significant at the level of $(0.05 \geq a)$ between the average scores of the experimental group and the control group average score in the post-test application for the experimental group

2. There are differences with statistically significant at $(0.05 \geq a)$ between the average scores of the experimental group in the pre/post test application in favor of the posttest application

3. There are differences with statistically significant at the level of $(0.05 \geq a)$ between the average scores of the experimental group and the control group average score in the post-test application to measure achievement motivation for the experimental group

4. There are differences with statistically significant at $(0.05 \geq a)$ between the average scores of the experimental group in the pre/ post test application to measure achievement motivation in favor of the post-test application

\section{RESEARCH LIMITS}

1. This study was limited to build an electronic program to three educational units of the English language course that are being studied by e-learning management system (JUSUR)

2. This study was limited to the female students of the preparatory year at the Hashemite UniversityFaculty of Arts and Sciences who are studying English language course

3. This study was applied in the summer semester of the academic year (2015-2016)

\section{RESEARCH TERMS}

1. E-Learning Management System (LMS): packaged integrated programs make up a system for the management of the educational process.

2. (JUSUR) System: an integrated Learning Management system based on remote educational process management and offers all required functions to support e-learning through a number of integrated systems. So as to facilitates the process of interaction between the student and faculty member and allow at the same time to follow up and monitor the progress of the educational process.

3. Knowledge acquisition: knowledge obtained by the individual through a program and curriculum with a view to adapt it to the medium and course study Japelln referred that the level of achievement of specified performance or efficiency in the academic work, also resides on the part of teachers or through standardized tests or both

4. Motivation: Motivation is internal motive that drives an individual's behavior and guided to reach a certain goal, and to satisfy the need to achieve a goal

Motivation is a form of urgent exhibitionism that create some kind of activity or event

The motivation refers to the total internal and external conditions that drive the individual to rebalance that misfire, motive in this sense refers to the tendency to reach a particular goal

\section{Previous Studies}

Since previous studies help in the formation of a comprehensive vision for the steps of any study, the researcher to access to a range of studies on e-learning and regulations and their impact on the educational process and the latest study (Qarni,1427), which was designed to evaluate the experience of King Saud University use WEBCT system over the Internet, and it was the most important findings of the researcher that the responses of faculty members in the field of knowledge-based WEBCT was between medium and high, while the responses in the use of WEBCT system in supporting the teaching was among the weak and high, due to the weakness of teacher training WEBCT to use the system, either the students have found that their knowledge of the applications of the system was 
The Effect of Using the E-Learning Management System (Jusur) on Knowledge Acquisition in the English Language and Achievement Motivation for Preparatory Year Students at the Hashimite University: An Empirical Study

weak, and that seeking WEBCT system in the study of their courses were also weak, because the number of items offered through WEBCT system limited the university and it's in the testing phase

In a study (Zamil,1424) study sought to evaluate e-learning experience in each of the Arab Open University in Riyadh and the General Organization for Technical Education and Vocational Training from the student's perspective, the study sample consisted of 256 students so that represents male $78.5 \%$ of the study sample, while representing female ratio of $21.5 \%$, the study showed that students interact with e-learning affected by the lack of clarity in the way of e-learning many of them for the number, and the possibility of the application of e-learning depends on factors such as students mastering computer and familiarity with technology to use, and that a large proportion of the study sample expressed that the material costs of Internet access and the lack of a professor when you need him the most prominent obstacles to e-learning.

In the context of the study (Williams et al., 2006) found that the teachers realized a higher level of interaction and cooperation among students and between teachers and students, and that teachers appeared more convinced with achievement of what they have gained from the learning environment via the Internet, and that students prefer the environment where they can access the courses through the Internet with an easy and comfortable way.

While the study carried out by the (Cramer, Collins, Sinder\& Fawsett, 2006) was intended to make a comparison between regular classes students and students enrolled online in terms of their use of virtual classroom, perceptions and the benefits they have achieved, and the results showed a relationship between use ofthe virtual lecture Hall and achieving the highest results in half-year exam, and students applauded the idea of virtual hall with a high degree.

The study (al-Dakhil,1428) which aimed to monitor the views of members of the Faculty of Education at King Saud University towards the use of e-learning in higher education, concluded that $86.7 \%$ need to attend training courses in the field of e-learning, and that $91.1 \%$ believe that the presence of courses based according to educational standards will raise the efficiency of e-learning, and $75.6 \%$ believe that e-learning is better than the traditional methods of learning.

And when the researcher asked about obstacles to the use of e-learning, the sample responsesresults were as the following:

$85.6 \%$ of the sample believes that the most important reasons not to create students to use e-learning

$83.3 \%$ agreed on the lack of clarity of the methods which have effective

$80 \%$ agreed on the lack of technical skills of faculty members

The Eldakheel study pointed to a study of (Orengreen, 2004), which was designed to evaluate education environment based one-learning.and the focus has been on design, use, skills, evaluated users during the interaction with the e-learning environment.

The sample results from the Copenhagen Business School (CBS) revealed the following: The level of education in the sample improved significantly, the designer of the project helped to increase positive attitudes among students when using electronic learning environments.

Study Quality Assessment System (Jusur) for the management of e-learning

Evaluation system has been studied (Jusur) for e-learning through two phases:

First, assess the quality system (Jusur) using standard

\section{THE Field STUdY}

Researcher chose the Hashemite University in Jordan to conduct field study them

Table shows the number of students in the two groups

\begin{tabular}{|c|c|}
\hline \multicolumn{2}{|c|}{ School classes } \\
\hline Groups & Number of Students \\
\hline The Control Group(2/2) & 25 students \\
\hline The Experimental Group (2/1) & 25 Students \\
\hline
\end{tabular}

Homogeneity of the students' number in each group became 25 students 


\section{Pretest Application for the Research Tools}

Before starting the lessons of the program's activities was conducted tribal application of the two tests, (e-learning program (Jusur) on the acquisition of knowledge in the English language and achievement motivation students have a preparatory year, Jordanian) on the control and experimental groups students in the period from 22/09/2016 to 25 / 9/2016

Calculate the average difference between the students of control and experimental groups before the start of field testing: The researcher compares the degrees of control and experimental groups for elearning program students (Jusur) on the acquisition of knowledge in the English language and achievement motivation students have a preparatory year, those grades were monitored in the payroll so the work of appropriate statistical analysis

A table showing the value of $(\mathrm{T})$ in terms of the difference between the mean scores of the two groups in the pretest application

\begin{tabular}{|l|c|c|c|l|l|c|}
\hline \multicolumn{1}{|c|}{ Group } & $\mathrm{M}$ & $\mathrm{P}$ & $\mathrm{N}$ & Degree of freedom 2 (n -1) & value of $(\mathrm{t})$ & statistical significance \\
\hline Experimental & 21.68 & 2.2929 & 25 & 48 & $\begin{array}{l}\text { Calculated } \\
1.3760\end{array}$ & $\begin{array}{c}\text { It is not statistically } \\
\text { significant }\end{array}$ \\
\hline control & 20.8 & 2.1354 & & & $\begin{array}{l}\text { Tabulated } \\
2: 06\end{array}$ & \\
& & & & & \\
\hline
\end{tabular}

It is seen from the above table that the value of ( $t$ ) calculated is 1.3760 less than the value of $(\mathrm{T})$ Tabulateda 2:06, so they are not statistically significant on the level (0.05), and therefore does not have a statistically significant difference between the mean scores of the experimental group students and the control group students in tribal Application.

\section{For the E-Learning Program (Jusur)}

A table showing the value of $(\mathrm{T})$ in terms of the difference between the mean scores of pretest Application

\begin{tabular}{|l|c|c|c|c|l|c|}
\hline Group & $\mathrm{M}$ & $\mathrm{P}$ & $\mathrm{N}$ & degree of freedom 2 (n -1) & value of $(\mathrm{t})$ & statistical significance \\
\hline Experimental & 21.52 & 1,6998 & 25 & 48 & $\begin{array}{l}\text { Calculated } \\
0.8906\end{array}$ & $\begin{array}{c}\text { It is not statistically } \\
\text { significant }\end{array}$ \\
\hline control & 20.96 & 2.5687 & & & $\begin{array}{l}\text { Tabulated } \\
2: 06\end{array}$ & \\
\hline
\end{tabular}

It can be seen from the above table that the value of (t) calculated is 0.8906 less than the value of $(\mathrm{T})$ tabulated 2:06, so they are not statistically significant on the level (0.05), and therefore does not have a statistically significant difference between the mean scores of the experimental group students and the control group students in the tribal application to test Performing positions

\section{Sixth: The Teaching Program Content for Students of the Experimental GROUP}

Teaching content took nine weeks, where the researcher started at 22/09/2016 and finished teaching at 30/11/2016 During this period, the researcher met with students from over 27 interviews (three sessions per week) At the beginning of each meeting the researcher format the students so that does not happen separation between these meetings, and so linked to this setting as already explained, and what will be displayed, and were as follows:

\section{The First MeEting}

Where the researcher initially offering an introductory lesson on using the tutorial teaching instead of the traditional way, with an explanation of the steps to implement the teaching, as well as providing illustrative examples of the teaching strategies included educational program and to clarify its steps.

\section{The SECOND MEETING}

Where the researcher as to the definition of a group of students and the aim of the teaching program, as well as active in a simple, clarifying, helping students on a clear understanding of the general framework of the content before going into the study, and the rest of Meetingsgo the same previous pattern and with the change in the teaching aids and educational activities, as well as the diversification in instructional strategies, depending on the nature of the teaching position in light of the tutorial 
The Effect of Using the E-Learning Management System (Jusur) on Knowledge Acquisition in the English Language and Achievement Motivation for Preparatory Year Students at the Hashimite University: An Empirical Study

\section{Seventh: Post-Test ApPlication of Research ToOlS}

After the researcher finishing the teaching content of the program and taking into account the scientific disciplines that have been identified in the research, the researcher conducting the post-test application of research tools, where the post-test application (mail program (Jusur) to the students of the experimental group and control group students in the period from 16/12/2016 until 20/12/2016 to identify the extent of the growth and improvement of the students to acquire certain cognitive skills attainment and achievement motivation in the subject of English for the students of the preparatory year

After students answer (acquisition) researchertests, then he corrects this stock and estimate grades for each student of the research group, so that the results can be highlighted and analyzed and processed inhalers statistical methods, a way that achieves the goals of research and allows testing the validity of statistical hypotheses .

\section{Results OF THE RESEARCH}

To answer the first question of the research questions: to what effect the program used in the English language course through e-learning management system (Jusur) on the (acquisition) of knowledge in English language students have a preparatory year

So that the proposed changes tutorial incident ushered in society, and even contribute to the achievement of the objectives of the teaching of educational content contained active educational program, it must be based on a set of scientific basics to ensure suitability

So after looking at their research and studies related to the proposed educational program, and the search is over a group of foundations upon which the proposed educational program are as follows:

- Taking into account the nature and characteristics of the learner

- Determine the general goals and procedural scientific content

- Identify and organize scientific content

- The organization of the educational environment

- Make learner the focal axis when implementing educational Active

- Messaging boosters

- Positive and active participation of the learner

- Logical sequence of diverse educational activities in accordance with the position of the educational lesson

- Active educational and scientific environment and attitudes of children link

- Diversification in the use of teaching strategies in accordance with the constructivist learning depending on the nature of the teaching position

- Diversification in the use of teaching aids, commensurate with the nature of the teaching position

- Evaluation of all implementation stages of the educational activities through the implementation of thetutorial steps

To answer the second question of the research questions: What is the impact of the program used in the English language course through e-learning management system (Jusur) on achievement motivation in English language for female students of the preparatory year

By looking at previous studies and research conducted in the area to extract the associated menus and display those lists on the specialists surveyed, the researcher collects the results and conduct statistical treatment to indicate the health of the assumptions underlying the search..

One of the most important findings of the researcher:

1. There are differences with statistically significant at the level of $(0.05 \geq a)$ between the average scores of the experimental group and the control group average score in the post-test application for the experimental group 
2. There are differences with statistically significant at $(0.05 \geq a)$ between the average scores of the experimental group in the pre/ post test application in favor of the posttest application

3. There are differences with statistically significant at the level of $(0.05 \geq a)$ between the average scores of the experimental group and the control group average score in the post-test application to measure achievement motivation for the experimental group

4. There are differences with statistically significant at $(0.05 \geq a)$ between the average scores of the experimental group in the pre/ post test application to measure achievement motivation in favor of the post-test application

The most important recommendations of the research:

Researcher presented a set of recommendations and proposals in the light of this, the most important need to train all students to use e-learning management system (Jusur), and dealing with the services provided by this system, which, in addition to the need to establish a unit to develop e-learning for the Universities of Jordan to our attention the development of e-courses and submit through e-learning management system (Jusur).

\section{REFERENCES}

[1] Ibrahim bin Abdullah Muhaisin (2002): "E-learning ... a luxury or a necessity ...?!" Working paper introduced to School of the Future Symposium, College of Education, King Saud University, from October 22 to 23 available at: site http // www. dr-mutawa.com/e-learningarabic.htmhttp://www.alyaseer.gov.sa/forum/topic.asp

[2] JamilAtmezi. (2007). Introduction to e-learning. And it can be retrieved from the site: http://elearning.ppu.edu/mod/resource/view.php?id=828

[3] Zamil, Zakaria Abdullah: "Evaluation of e-learning experience in some institutions of higher education in the Kingdom of Saudi Arabia from the student's point of view" (Umm Al-Qura University site) http://uqu.edu.sa/page/ar/150086-

[4] Said bin Vasa Ahmed Al-Qarni assessment of King Saud University's experience in the use of WebCT system through the Global Information Network "Internet" in supporting the teachingCollege of Education Research Center, King Saud University, is available through: http://www.nooonbooks.com

[5] Abdul Rashid Hafiz, Hana Aldhoi. "Sources of information available on the Internet: proposed standards for evaluation." Cybrarians Journal.- p 10 (September 2006) - Available at: http://ww w.cybrarians.info/journal/no10/resources.

[6] Mousa, Abdullah bin Abdul Aziz (1423), e-learning concept, its characteristics, benefits, drawbacks, .working paper submitted to the School of the Future Symposium, King Saud University -College of Education-url: https://www.kfu.edu.sa/

[7] MashaeilAbdul-Aziz al-Dakhil. study of the views of members of the Faculty of Education at King Saud University towards the use of e-learning in higher education -Unpublished MA Thesis, Faculty of Education, King Saud University, 2007

[8] Hend Bent Suleiman al-Khalifa. Recent trends and developments in e-learning service: comparative study between the four models of on line education. College of Computer and Information Systems - King Saud University .1423

[9] Haifa Bent Fahd Almberek. Develop lecture method in university education using e-learning with suggested model worksheet introduced to the School of the Future Symposium in the period 16-17 / 8/1423, King Saud University

[10] Alyahyaai L.M (2005).challenges for implementing an e-learning environment in omani higher education colleges: how learning resources center management can play a vital supporting role. Ibri College of education-sultanate of oman. retrieved December 24,2007 from: www. mohe.gov.om

[11] The association of real estate licene law officials. Arello distance education evaluation form. retrieved January 24,2008 from: www.arello.net

[12] Clayton R. Wright. Criteria for evaluating the quality of online courses. Instructional Media and design. GrantMacEwan College .retrieved January22, 2008, from: www.imd. macewan.ca/imd/ content 
The Effect of Using the E-Learning Management System (Jusur) on Knowledge Acquisition in the English Language and Achievement Motivation for Preparatory Year Students at the Hashimite University: An Empirical Study

[13] Commonwealth of Australia. (2005).e-learning course evaluation retrieved January22, 2008, from:www.industry.flexiblelearning.net.au/guide/resources/learner_eval

[14] Kenneth M. Carmer (2006).virtual lecture hall for in calass and online sections: a comparison of utilization, perceptions and benefits .journal of research on technology in education,38(4).371381 retrieved January22,2008,from: www.industry.flexiblelearning.net.au/guide/ 